\title{
Ventral Tegmental Area Leptin Receptor Neurons Specifically Project to and Regulate Cocaine- and Amphetamine-Regulated Transcript Neurons of the Extended Central Amygdala
}

\author{
Rebecca L. Leshan, ${ }^{1,2 *}$ Darren M. Opland, ${ }^{1,3 \star}$ Gwendolyn W. Louis, ${ }^{1,2}$ Gina M. Leinninger, ${ }^{1}$ Christa M. Patterson, ${ }^{1}$ \\ Christopher J. Rhodes, ${ }^{4}$ Heike Münzberg, ${ }^{1}$ and Martin G. Myers Jr ${ }^{1,2,3}$ \\ ${ }^{1}$ Division of Metabolism, Endocrinology, and Diabetes, Department of Internal Medicine, ${ }^{2}$ Department of Molecular and Integrative Physiology, and \\ ${ }^{3}$ Program in Neuroscience, University of Michigan, Ann Arbor, Michigan 48109, and ${ }^{4}$ Kovler Diabetes Center, University of Chicago, Chicago, Illinois 60637
}

\begin{abstract}
Leptin acts via its receptor (LepRb) to regulate neural circuits in concert with body energy stores. In addition to acting on a number of hypothalamic structures, leptin modulates the mesolimbic dopamine (DA) system. To determine the sites at which LepRb neurons might directly influence the mesolimbic DA system, we examined the distribution of LepRb neurons and their projections within mesolimbic brain regions. Although the ventral tegmental area (VTA) contains DA LepRb neurons, LepRb neurons are absent from the amygdala and striatum. Also, LepRb-EGFPf mice (which label projections from LepRb neurons throughout the brain) reveal that few LepRb neurons project to the nucleus accumbens (NAc). In contrast, the central amygdala $(\mathrm{CeA})$ and its rostral extension receive copious projections from LepRb neurons. Indeed, LepRb-specific anterograde tracing demonstrates (and retrograde tracing confirms) that VTA LepRb neurons project to the extended CeA (extCeA) but not the NAc. Consistently, leptin promotes cAMP response element-binding protein phosphorylation in the extCeA, but not NAc, of leptin-deficient animals. Furthermore, transgenic mice expressing the trans-synaptic tracer wheat germ agglutinin in LepRb neurons reveal the innervation of CeA cocaine- and amphetamine-regulated transcript (CART) neurons by LepRb neurons, and leptin suppresses the increased CeA CART expression of leptin-deficient animals. Thus, LepRb VTA neurons represent a subclass of VTA DA neurons that specifically innervates and controls the extCeA; we hypothesize that these neurons primarily modulate CeA-directed behaviors.
\end{abstract}

\section{Introduction}

The adipose-derived hormone leptin conveys the adequacy of nutritional reserves to the CNS, where it acts to permit energy expenditure, decrease feeding, and modulate a number of other behaviors; low leptin levels promote opposite responses (Friedman, 2002; Elmquist et al., 2005; Morton et al., 2006; Berthoud, 2007; Gao and Horvath, 2007; Myers et al., 2009). Leptin acts via the long form of the leptin receptor (LepRb) on specific populations of CNS neurons to mediate most leptin actions (Cohen et al.,

\footnotetext{
Received Feb. 24, 2010; accepted March 17, 2010.

This work was supported by National Institutes of Health (NIH) Grants DK057768 and DK078056, by the Marilyn H. Vincent Foundation, and by grants from the American Diabetes Association (M.G.M.) and the American Heart Association (M.G.M., H.M., and R.L.L.). We thank Amylin Pharmaceuticals for the generous gift of leptin. We thank Dr. Yoshihiro Yoshihara for the gift of the WGA plasmid, Dr. Yuchio Yanagawa for Gad $7^{\text {GFP }}$ mice, and Dr. Corrinne Lobe for the iZAP plasmid. We thank Yusong Gong for excellent technical assistance in the development of mouse models and adenoviruses. Core support was provided by the University of Michigan Cancer Center (NIH Grant CA46592) and the University of Michigan Diabetes Research and Training Center (NIH Grant DK20572).

*R.L.L. and D.M.O. contributed equally to this work.

Correspondence should be addressed to Dr. Martin G. Myers, Jr., Division of Metabolism, Endocrinology, and Diabetes, Department of Medicine, University of Michigan Medical School, 5560 MSRB II/0678, 1150 West Medical Center Drive, Ann Arbor, Ml 48109. E-mail: mgmyers@umich.edu.

H. Münzberg's present address: Pennington Biomedical Research Center, Louisiana State University System, 6400 Perkins Road, Baton Rouge, LA 70808. E-mail: heike.munzberg@pbrc.org.

DOI:10.1523/JNEUROSCI.1001-10.2010

Copyright $\odot 2010$ the authors $\quad 0270-6474 / 10 / 305713-11 \$ 15.00 / 0$
}

2001; de Luca et al., 2005). LepRb-expressing neurons lie in numerous regions involved in the regulation of energy balance, including mediobasal hypothalamic $(\mathrm{MBH})$ "satiety centers" [e.g., the arcuate nucleus (ARC)], as well as the lateral hypothalamic area (LHA), the midbrain, and the brainstem (Figlewicz et al., 2006; Fulton et al., 2006; Grill, 2006; Hommel et al., 2006; Leinninger et al., 2009; Leshan et al., 2009; Myers et al., 2009; Scott et al., 2009; Hayes et al., 2010).

A number of aspects of leptin action in the $\mathrm{MBH}$ are beginning to be unraveled, including the role of leptin in regulating LepRb/pro-opiomelanocortin (POMC)-expressing neurons and their opposing LepRb/agouti-related protein (AgRP)/neuropeptide Y-expressing neurons in the ARC (Elmquist et al., 2005; Morton et al., 2006; Berthoud, 2007; Gao and Horvath, 2007; Huo et al., 2009). These neurons regulate satiety and thus mediate an important component of the anorectic response to leptin, as well as modulate energy expenditure and aspects of glucose homeostasis. Many data suggest that the action of leptin on these LepRb-expressing $\mathrm{MBH}$ neurons only accounts for a fraction of leptin action, however (Balthasar et al., 2004; Dhillon et al., 2006; DiMicco and Zaretsky, 2007; Huo et al., 2009; Leinninger et al., 2009; Myers et al., 2009; Yadav et al., 2009). Indeed, MBH LepRb neurons represent a minority of LepRb-expressing neurons in the 
brain (Myers et al., 2009; Scott et al., 2009). Thus, populations of LepRb neurons in other brain areas must play crucial roles in leptin action.

In addition to regulating satiety, leptin regulates the incentive value of food and other rewards and suppresses depression and anxiety-like behaviors (Fulton et al., 2000; DiLeone et al., 2003; Figlewicz et al., 2006; Lu et al., 2006; Liu et al., 2009). The mesolimbic dopamine (DA) system, which arises from DAergic neurons in the ventral tegmental area (VTA), mediates important aspects of incentive salience for food and contributes to other aspects of emotion and behavior (DiLeone et al., 2003; Kelley et al., 2005; Nestler, 2005). These VTA DA neurons send important projections to limbic structures, such as the striatum [including the nucleus accumbens (NAc) ] and the extended amygdala complex. Although the historical tendency has been to consider the VTA DA neurons en bloc, a variety of recent observations suggest differing projection patterns, gene expression, regulation, and electrophysiologic properties for distinct subsets of these cells (Ikemoto, 2007; Lammel et al., 2008; Margolis et al., 2008).

Leptin modulates DA-dependent measures of food and drug reward, and LepRb-expressing VTA neurons and VTAregulating LHA LepRb neurons have been described previously (Fulton et al., 2000, 2006; Figlewicz et al., 2006; Hommel et al., 2006; Leinninger et al., 2009). Many questions remain regarding the sites and mechanisms whereby leptin might influence the mesolimbic DA system, however, and the direct projections from LepRb neurons into and within the mesolimbic DA system have not been examined systematically. Also unknown are the potential distinctions between LepRb-expressing and other (non-LepRb) VTA neurons. In this study, we elucidate neural mechanisms by which leptin may control the mesolimbic DA system by revealing the distribution of LepRb neurons and their projections in mesolimbic brain regions, along with evidence for the regulation of the identified target regions by leptin.

\section{Materials and Methods}

Materials. Recombinant mouse leptin was a generous gift from Amylin Pharmaceuticals. A fluorogold (FG) equivalent, hydroxystilbamidine, was purchased from Biotium. Rabbit anti-phosphorylated cAMP response elementbinding protein (pCREB) was from Cell Signaling Technology, rabbit anti-cFos was from Calbiochem, rabbit anti-FG was from Millipore, chicken anti-green fluorescent protein (GFP) was from Abcam, rabbit anti-cocaine- and amphetamineregulated transcript (CART) was from Phoenix Pharmaceuticals, goat

A interfascicular nucleus.
(LepRb Neurons Only)
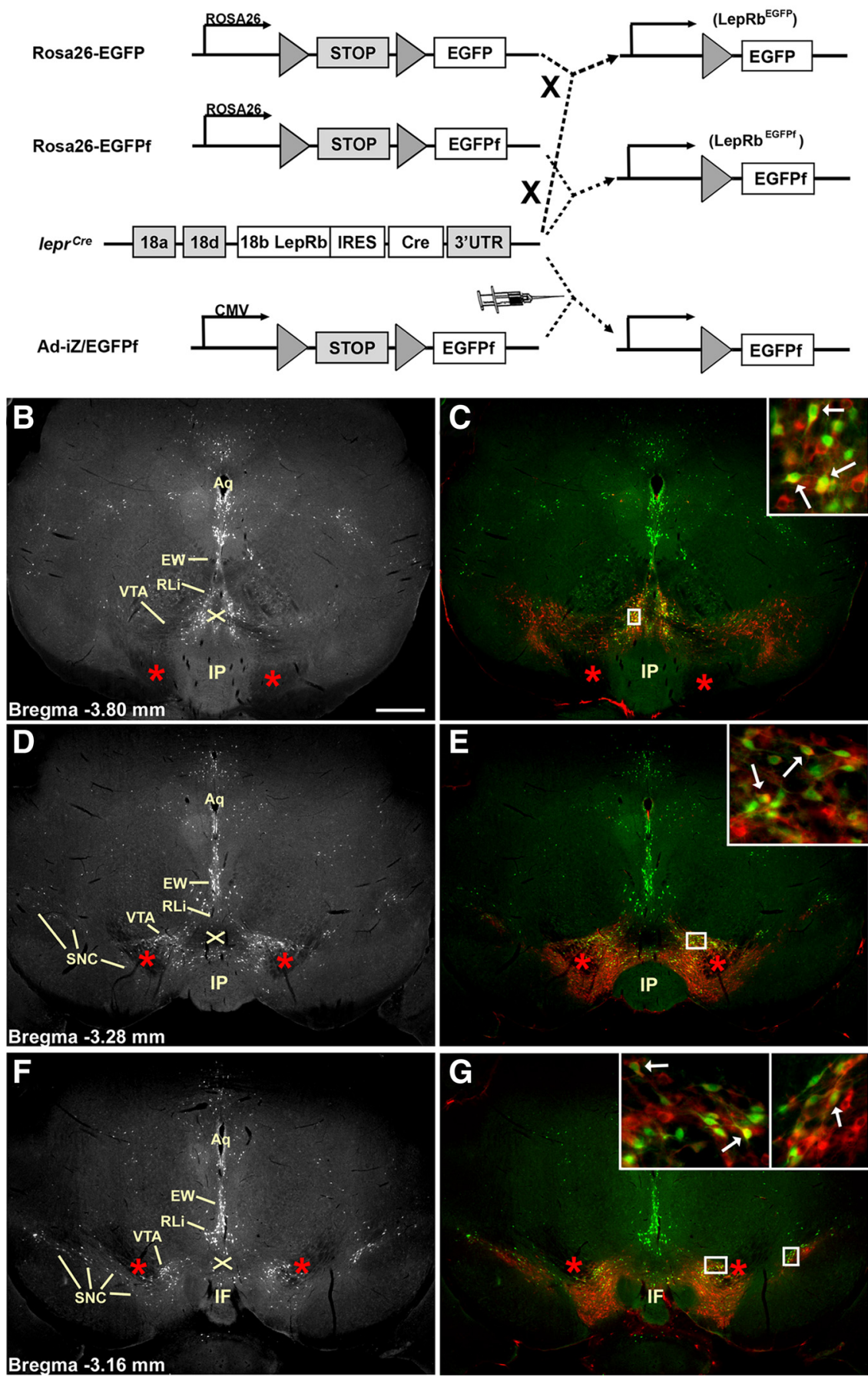

Figure 1. Mouse models and the visualization of midbrain LepRb neurons. A, Schematic of methods for expression of EGFP or EGFPf in LepRb neurons. Combining Lepr re with Rosa26-EGFP or Rosa26-EGFPf alleles results in the stable expression of EGFP or EGFPf in LepRb neurons in LepRb ${ }^{\text {EGFP }}$ and LepRb ${ }^{\text {EGFPF }}$ mice, respectively (top). Additionally, injection into Lepr ${ }^{\text {re }}$ mice of the adenoviral Ad-iZ/EGFPf promotes cre-mediated EGFPf expression in LepRb neurons surrounding in the injection site (bottom). $3^{\prime}$ UTR, $3^{\prime}$ untranslated region. $\boldsymbol{B}, \boldsymbol{D}, \boldsymbol{F}$, LepRb-expressing neurons revealed by EGPF immunoreactivity through the rostrocaudal extent of the midbrain of LepRb ${ }^{\mathrm{EGFP}}$ animals. C,E, G, Colocalization of EGFP (green) and TH (red) immunoreactivity through the rostrocaudal extent of the midbrain of LepRb ${ }^{\text {EGFP }}$ mice. Insets show digital zooms of the boxed areas; arrows demonstrate examples of colocalized neurons. Red asterisks indicate the medial lemniscus; $\times$ indicates the ventral tegmental decussation. Scale bar, $200 \mu \mathrm{m}$. Aq, Central aqueduct; IP, interpeduncular nucleus; IF,

anti-wheat germ agglutinin (WGA) was from Vector Laboratories, and goat anti- $\beta$-gal was from Biogenesis. Normal donkey serum (NDS) and biotinylated donkey anti-rabbit were purchased from Jackson ImmunoResearch. Alexa 488-conjugated donkey anti-rabbit, 

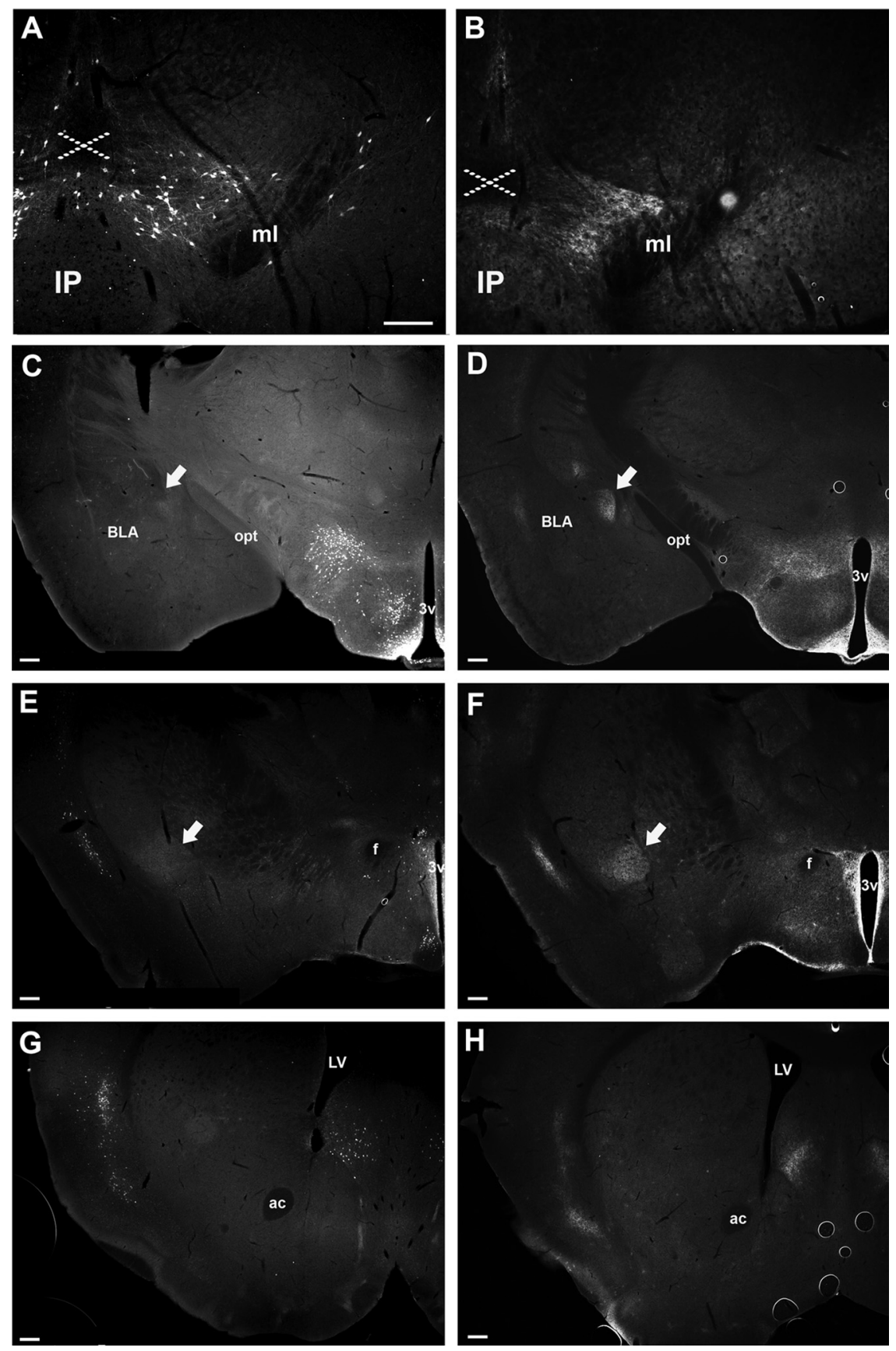

Figure 2. Detection of LepRb neurons and projections throughout the mesolimbic DA system in LepRb ${ }^{\text {EGFP }}$ and LepRb EGFPf mice. $\boldsymbol{A}-\boldsymbol{H}, \mathrm{EGFP}$ immunoreactivity in the midbrain $(\boldsymbol{A}, \boldsymbol{B})$, hypothalamus and amygdala $(\boldsymbol{C}, \boldsymbol{D})$, rostral hypothalamus and $\operatorname{IPAC}(\boldsymbol{E}$, $\boldsymbol{F}$ ), and striatum and BNST $(\boldsymbol{G}, \boldsymbol{H})$ of LepRb ${ }^{\text {EGFP }}$ (left) and LepRb ${ }^{\text {EGFPf }}$ (right) mice is shown. Arrows in $\boldsymbol{C}$ and $\boldsymbol{D}$ indicate the CeA; arrows in $\boldsymbol{E}$ and $\boldsymbol{F}$ indicate the IPAC. The dashed $X$ indicates the ventral tegmental decussation. Scale bars, $200 \mu \mathrm{m}$. ml, Medial lemniscus; IP, interpeduncular nucleus; opt, optic tract; $3 v$, third ventricle; f, fornix; LV, lateral ventricle; ac, anterior commissure.

Alexa 488-conjugated goat anti-chicken, and Alexa 568-conjugated goat anti-rabbit were purchased from Invitrogen. The ABC Vectastain Elite kit was purchased from Vector Laboratories. All other immunohistochemical supplies were purchased from Sigma.

Animals. Lep $p^{o b / o b}$ animals were purchased from The Jackson Laboratory. All other animals were housed and bred in our colony and according to guidelines approved by the University of Michigan Committee on the Care and Use of Animals. Mice were given ad libitum access to food and water and were housed in groups of two to four until surgery, after which animals were housed individually. Lepr ${ }^{\text {cre/cre }}\left(\mathrm{LepRb}^{\mathrm{Cre}}\right)$ and Lepr $^{\text {cre/cre }}$; Gt(ROSA)26Sor ${ }^{\text {tm2Sho/tm2Sho (LepRb }}{ }^{\text {EGFP }}$ ) mice have been described and were generated by intercrossing homozygous animals within our facility (Leshan et al., 2006, 2009). Gad1 ${ }^{E G F P}$ mice (a generous gift from Dr. Y. Yanagawa, Gunma University, Gunma, Japan) (Abe et al., 2005) were propagated by heterozygote intercross. Gt (ROSA)26Sor ${ }^{\text {tm } 1 m g m j}$ [also known as Gt(ROSA)26Sor ${ }^{\text {EGFP }}$ or ROSA26EGFPf] animals were produced and interbred with LepRb ${ }^{\text {Cre }}$ mice to generate LepRb ${ }^{\text {EGFPf }}$ mice, as described previously (Leshan et al., 2009).

Generation of $i Z / W A P$ mice. The coding region for WGA was PCR amplified from the pBluescript II SK-WGA plasmid (a generous gift from Dr. Y. Yoshihara, RIKEN Brain Science Institute, Tokyo, Japan) and inserted into the iZ/AP vector (a generous gift from Dr. C. Lobe, University of Toronto, Toronto, Ontario, Canada) (Allen et al., 2006) downstream of the cytomegalovirus (CMV) promoterdriven floxed $\beta$-geo cassette. The resulting pCALL2-WGA/AP (iZ/WAP) plasmid was submitted to the University of Michigan transgenic core for production of transgenic embryonic stem (ES) cell clones. Four hundred eighty clones were screened for single copy number by quantitative PCR for neo sequences and also for $\beta$-gal expression via immunocytochemical staining ( $\beta$-gal staining kit; Roche). Five ES clones were expanded and rescreened, and three ES clones were injected into blastocysts and implanted into pseudopregnant females. The resulting chimeric male progeny were bred to $\mathrm{C} 57 \mathrm{BL} / 6$ females for the determination of germline transmission (by brown coat color) and PCR for the presence of Neo. Several F1 $i Z / W A P$ mice from each ES clone were perfused and screened for CNS $\beta$-gal expression by immunohistochemistry (IHC) using antibodies against $\beta$-gal. One $i Z / W A P$ line was determined to express the transgene ubiquitously in the CNS and was chosen for further study. Subsequent $i Z / W A P$ litters were genotyped by PCR using oligos derived from the WGA sequence (forward, AATGAGAAAGATGATGAGCACC; reverse, AGGTTGTTCGGGCATAGCTT). iZ/WAP mice were bred to mice containing LepRb ${ }^{\text {Cre }}$ to generate LepRb ${ }^{\text {WGA }}$ mice expressing WGA in LepRb neurons.

Tract tracers and stereotaxic surgery for microinjection. The generation of Ad-iZ/EGFPf and the production of concentrated, purified adenoviral stocks were as described previously (Morton et al., 2003; Leshan et al., 2009). For all tract-tracing experiments, LepRb ${ }^{\text {Cre }}$ or LepRb ${ }^{\text {EGFP }}$ mice were anesthetized using isofluorane and placed in a stereotaxic frame. After exposing the skull, a guide cannula with a stylet was lowered into the target regions. Coordinates (from bregma) were as follows: VTA [anteroposterior (AP), $-3.2 \mathrm{~mm}$; mediolateral $(\mathrm{ML}),-0.5 \mathrm{~mm}$; dorsoventral (DV), $-4.3 \mathrm{~mm}$ ], lateral ventricle (AP, $-0.6 \mathrm{~mm}$; ML, $-1.0 \mathrm{~mm}$; DV, $-2.2 \mathrm{~mm}$ ), interstitial nucleus of the posterior arm of the anterior commissure (IPAC; AP, $-0.5 \mathrm{~mm}$; ML, $-2.5 \mathrm{~mm}$; DV, $-4.6 \mathrm{~mm}$ ), central amygdala (CeA; AP, $-1.2 \mathrm{~mm}$; ML, $-2.8 \mathrm{~mm}$; DV , $-4.8 \mathrm{~mm}$ ), NAc (AP, $+1.0 \mathrm{~mm}$; ML, $-1.4 \mathrm{~mm}$; DV, $-4.8 \mathrm{~mm})$. The stylet was removed and replaced by an injector, and either $10-20 \mathrm{nl}$ of $2 \% \mathrm{FG}$ equivalent (Sigma) to LepRb ${ }^{\text {EGFP }}$ mice or 200-250 $\mathrm{nl}$ of Ad-iZ/EGFPf to LepRb ${ }^{\text {Cre }}$ mice was injected to the tissue using a $500 \mathrm{nl}$ Hamilton syringe at a rate of $50 \mathrm{nl} / 30$ s. After $10 \mathrm{~min}$, the injector and cannula were removed from the skull, and the incision was sutured. Mice were then housed individually for 

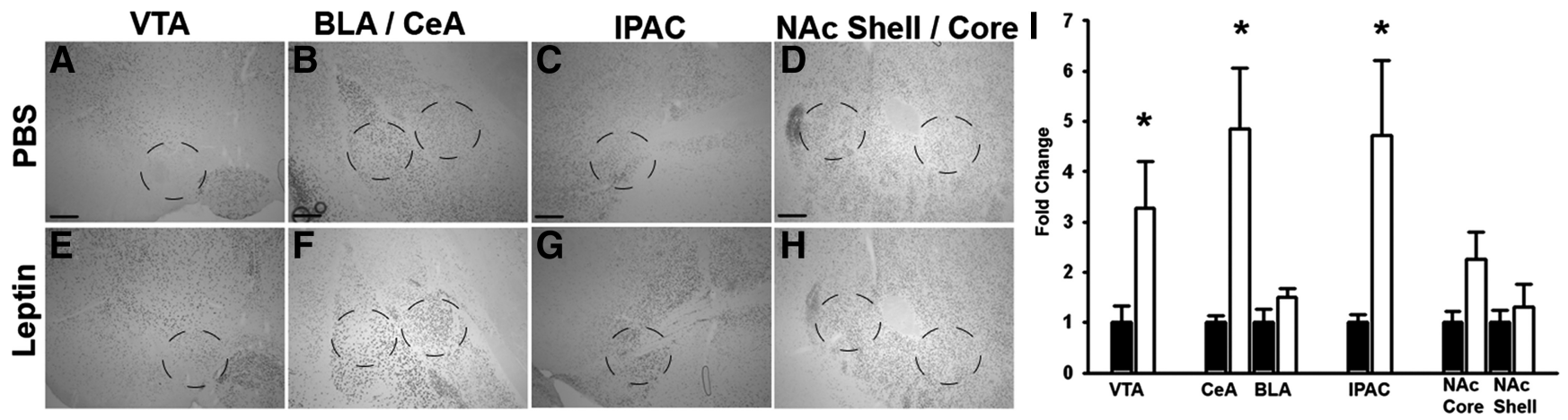

Figure 3. CREB phosphorylation in the midbrain, amygdala, and NAc of leptin-treated Lep ${ }^{o b / o b}$ mice. Leptin-deficient Lep $p^{o b / o b}(o b / o b)$ mice were treated with leptin $(5 \mathrm{mg} / \mathrm{kg}$, i.p., $2 \mathrm{~h})$ and perfused for the immunohistochemical detection of pCREB immunoreactivity. $\boldsymbol{A}-\boldsymbol{H}$, Representative images of pCREB immunoreactivity in VTA $(\boldsymbol{A}, \boldsymbol{E})$, amygdala $(\boldsymbol{B}, \boldsymbol{F}), \operatorname{IPAC}(\boldsymbol{C}, \boldsymbol{G})$, and NAC $(\boldsymbol{D}, \boldsymbol{H})$ of vehicle (top) and leptin-treated (bottom) animals. Circles denote regions analyzed for staining intensity, which is plotted as mean \pm SEM in $I . n=6$ for leptin treated and $n=5$ for PBS treated. ${ }^{*} p<0.05$. Scale bars, $100 \mu \mathrm{m}$.

A

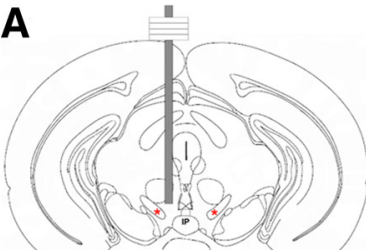

Bregma $-3.28 \mathrm{~mm}$

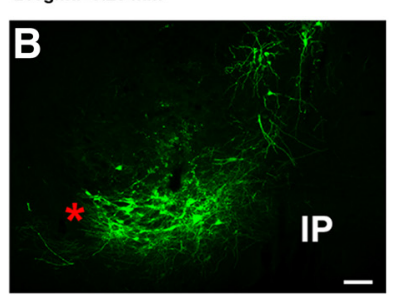

C

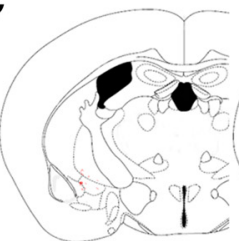

Bregma $-0.94 \mathrm{~mm}$

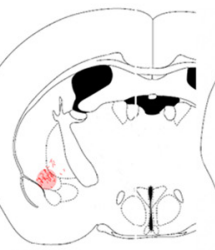

$-0.82 \mathrm{~mm}$

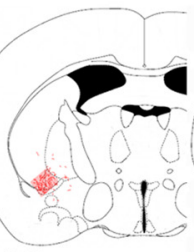

$-0.58 \mathrm{~mm}$

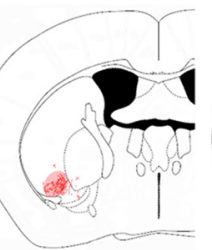

$-0.34 \mathrm{~mm}$

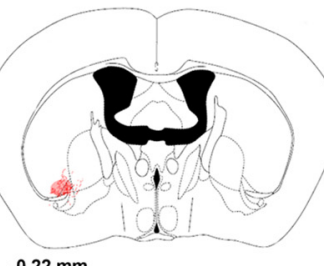

$-0.22 \mathrm{~mm}$
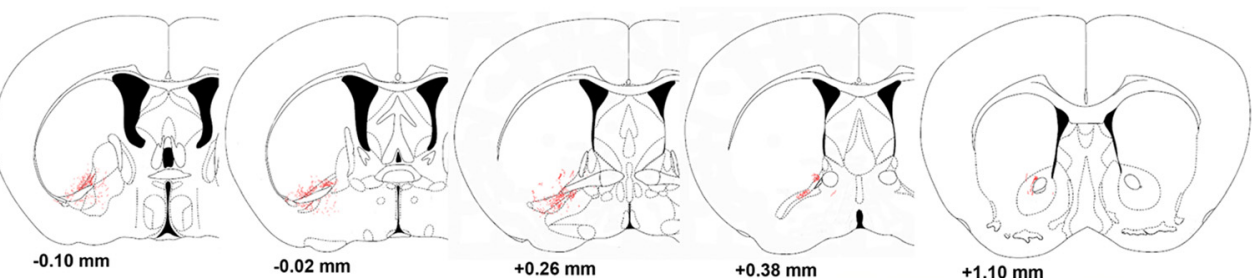

$+0.38 \mathrm{~mm}$
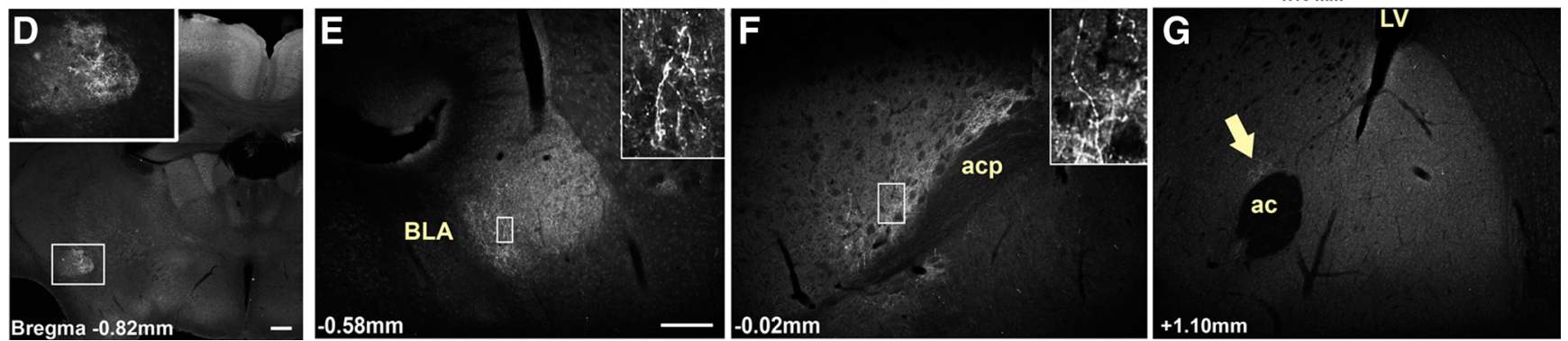

Figure 4. Representative Ad-iZ/EGFPf-mediated tracing of projections primarily from VTA LepRb neurons in Leprere mice. $\boldsymbol{A}, \boldsymbol{B}$, Schematic $(\boldsymbol{A})$ and EGFP immunoreactivity $(\boldsymbol{B})$ of the VTA injection site in a representative case. $\boldsymbol{C}$, The appearance of rostral projections (red) in this animal is superimposed on sections from the atlas of Paxinos and Franklin (2001). D-G, EGFP immunoreactivity in various regions to which VTA LepRb neurons sent detectable projections. Insets represent digital zooms of boxed regions. The arrow in $G$ indicates the small amount of NAc EGFP immunoreactivity observed in this and similar cases. Red asterisks indicate the medial lemniscus. Scale bars: $\boldsymbol{B}, \mathbf{D}, 200 \mu \mathrm{m} ; \boldsymbol{E}-\mathbf{G}, 100 \mu \mathrm{m}$. IP, Interpeduncular nucleus; acp, anterior commissure; ac, anterior commissure; LV, lateral ventricle.

either $3 \mathrm{~d}$ (FG-mediated retrograde tracing) or $5 \mathrm{~d}$ (Ad-iZ/EGFPfmediated anterograde tracing) before perfusion and processing.

Perfusion and IHC. Perfusion and IHC were performed as described previously (Münzberg et al., 2007). Briefly, mice were deeply anesthetized with a lethal dose of intraperitoneal pentobarbital $(150 \mathrm{mg} / \mathrm{kg})$ and perfused transcardially with sterile PBS, followed by either $4 \%$ paraformaldehyde or $10 \%$ formalin. Brains were removed, postfixed overnight, and dehydrated in a $30 \%$ sucrose solution. Brains were sectioned into 30 $\mu \mathrm{m}$ coronal slices, collected in four consecutive series, and stored at $-20^{\circ} \mathrm{C}$ in cryoprotectant until further use.

For IHC, sections were pretreated with $1 \% \mathrm{H}_{2} \mathrm{O}_{2}$ in ice-cold methanol, $0.3 \%$ glycine, and $0.3 \%$ SDS before blocking in NDS. Sections were then incubated with primary antibodies [chicken anti-GFP (1:1000), goat anti- $\beta$-gal (1:1000), mouse anti-tyrosine hydroxylase (TH; $1: 5000)$, rab- bit anti-pCREB (1:100), rabbit anti-CART (1:1000), or goat anti-WGA $(1: 1000)]$ overnight at $4^{\circ} \mathrm{C}$. Primary antibodies were detected either by immunofluorescence (anti-chicken-FITC, anti-rabbit Alexa 488, antimouse Alexa 568, anti-goat Alexa 568; all 1:200 dilution; Invitrogen) or by using the avidin-biotin/diaminobenzidine (DAB) method.

Mouse microdissection and analysis by quantitative PCR. Lep ${ }^{o b / o b}$ mice and their controls were treated and processed as described previously (Leinninger et al., 2009). Briefly, after a baseline day that included handling and vehicle (PBS) injections, mice were treated with either leptin (5 $\mathrm{mg} / \mathrm{kg}$, i.p.) or PBS every $12 \mathrm{~h}$ for $24 \mathrm{~h}$, during which food intake and body weight were measured. Mice were then anesthetized, and their brains were microdissected on a rodent coronal brain matrix $(1 \mathrm{~mm}$ divisions) and frozen on dry ice. RNA was prepared from microdissected tissue using TRIzol (Invitrogen) and converted to cDNA using the Su- 

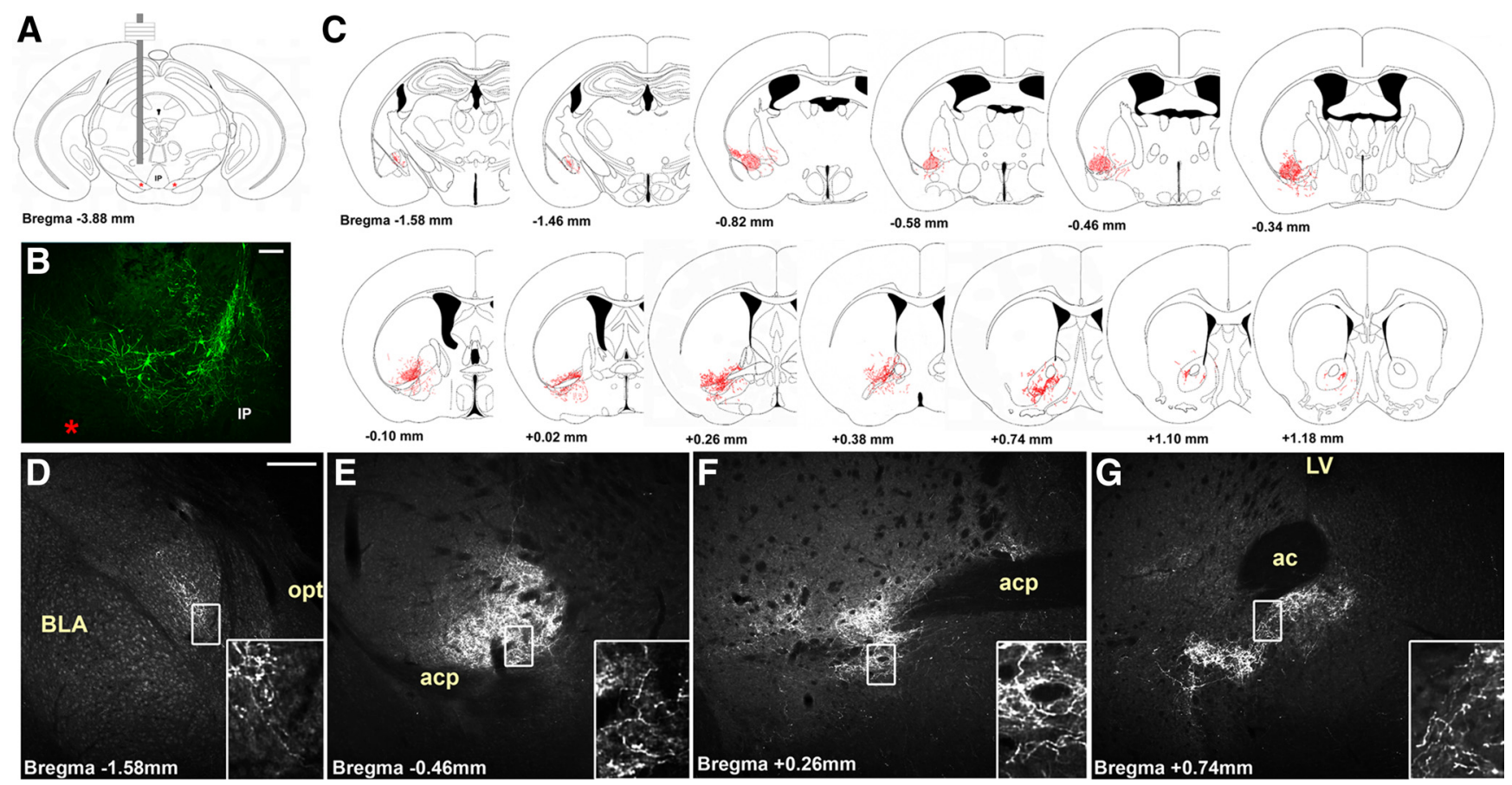

Figure 5. Representative Ad-iZ/EGFPf-mediated tracing of projections from VTA and midline midbrain LepRb neurons in Lepr ${ }^{\text {cre }}$ mice. $A, B, S$ chematic $(\boldsymbol{A})$ and EGFP immunoreactivity $(\boldsymbol{B})$ of the midbrain injection site in a representative case. C, The appearance of rostral projections (red) in this animal is superimposed on sections from the atlas of Paxinos and Franklin (2001). D-G, EGFP immunoreactivity in various regions to which midbrain LepRb neurons sent detectable projections. Insets represent digital zooms of boxed regions. Red asterisks indicate the medial lemniscus. Scale bars, $200 \mu \mathrm{m}$. IP, Interpeduncular nucleus; acp, anterior commissure; ac, anterior commissure; LV, lateral ventricle; opt, optic tract.

perScript First-Strand Synthesis system for reverse transcription (RT)PCR (Invitrogen). cDNA was analyzed in triplicate via quantitative RT-PCR for Gapdh (control gene) and Cart (both as supplied from Applied Biosystems) using a 7500 Real-Time PCR System (Applied Biosystems). Relative mRNA expression was calculated using the $2^{-\Delta \Delta \mathrm{CT}}$ method.

Image collection, data analysis, and statistics. For anterograde and retrograde tracing experiments, pictures of identical regions of brain nuclei were taken using filters for Alexa 488 or Alexa 568 as described previously (Münzberg et al., 2007). Confocal microscope images were taken on an Olympus Fluoview FV500 laser-scanning confocal microscope. Using Adobe Photoshop (Adobe Systems), images were overlaid in different RGB channels such that dual-labeled cells would become apparent. For quantification of pCREB, sections were processed in parallel for the detection of pCREB by DAB. Images of matched sections were taken under identical microscope conditions and opened using NIH ImageJ software. All images were converted into binary files using a standard threshold value for each set of matched images. The ratio of total area above threshold within a selection area (a circle 288 pixels in diameter) was compared between treatment groups for each brain region. Student's $t$ test was used to determine significance for the pCREB-immunoreactive (IR) area; one-way ANOVA with Bonferroni correction for multiple interactions was used to determine significance in Cart transcript changes.

\section{Results}

\section{LepRb-expressing midbrain neurons}

Reliable detection of LepRb protein in the mouse brain using LepR-specific antibodies remains problematic. To reliably identify LepRb-expressing CNS neurons, we thus crossed Lepr ${ }^{\text {cre }}$ mice (in which cre recombinase is expressed specifically in LepRb neurons) onto the Gt(ROSA)26Sor ${ }^{t m 2 S h o}$ (also known as ROSA26EGFP) background, in which cre-mediated deletion of a LoxPflanked (floxed), transcription-blocking Neo cassette results in the expression of enhanced GFP (EGFP) from the virtually ubiquitously expressed ROSA26 locus (Fig. 1A). The expression of cre recombinase from within the LepRb-specific mRNA gener- ated by the Lepr ${ }^{\text {cre }}$ allele predicts the LepRb specificity of the cre-induced EGFP expression in LepRb ${ }^{\text {EGFP }}$ mice, and EGFP expression in these animals coincides with functional LepRb (Leinninger et al., 2009; Leshan et al., 2009). EGFP expression in neural soma in the brains of these LepRb ${ }^{\text {EGFP }}$ mice thus reveals and facilitates the study of LepRb neurons.

The presence of EGFP-IR cells in the midbrain of LepRb ${ }^{\text {EGFP }}$ mice is consistent with previous reports of LepRb-containing soma in the VTA by the criterion of leptin-induced (LepRbdependent, cell-autonomous) STAT3 phosphorylation (pSTAT3) (Fulton et al., 2006; Hommel et al., 2006). EGFP-IR neurons in the caudal midbrain are located predominantly in midline nuclei, including the Edinger-Westphal (EW) and linear raphe (RLi), as well as in the medial aspects of the VTA (Fig. $1 B, C$ ). The middle and rostral portions of the midbrain contain a large number of EGFP-IR neurons in the DAergic portions of the VTA and the substantia nigra pars compacta $(\mathrm{SNc})$, as well as in the same medial nuclei as in the caudal midbrain (Fig. $1 D-G$ ). A total of $74.9 \pm 3.9 \%$ (SEM; $n=6$ ) of EGFP-IR cells in the VTA and $>95 \%$ of SNc EGFP-IR neurons colocalize with TH immunoreactivity, consistent with the DAergic nature of the majority of midbrain LepRb neurons. Of the TH-containing VTA neurons, $\sim 6 \%$ expressed EGFP, suggesting that LepRb neurons represent a relatively small and potentially specialized subset of VTA DA neurons.

LepRb projections to the limbic regions of the mesolimbic DA system primarily target the extended CeA

Since standard cytoplasmic EGFP reveals neural soma but poorly labels long projections (such as axons), we also used ROSA26EGFPf mice, in which cre recombinase-mediated excision of a transcription-blocking cassette induces the expression of a farnesylated EGFP (EGFPf) from the ROSA26 locus (Fig. 1) (Leshan et al., 2009). Farnesylation localizes EGFPf to the membrane, effec- 
tively labeling even very long axonal projections (Zylka et al., 2005; Leinninger et al., 2009; Leshan et al., 2009). We crossed ROSA26-EGFPf animals to Lepr ${ }^{\text {cre }}$ mice to generate LepRb ${ }^{\text {EGFPf }}$ mice with which to study projections from cre-expressing LepRb neurons (Leshan et al., 2009).

To determine the potential points of direct interaction between LepRb neurons and brain regions integral to the mesolimbic DA system, we examined the midbrain and extended amygdala/striatum of LepRb ${ }^{\text {EGFP }}$ and LepRb ${ }^{\text {EGFPf }}$ mice for the presence of EGFP-IR soma and projections, respectively (Fig. 2). With respect to soma, in contrast to the midbrain, no EGFP-IR cell bodies were detected in the extended amygdala or striatum of LepRb ${ }^{\text {EGFP }}$ mice, suggesting that these regions do not contain LepRb neurons (Fig. 2 ). This result is consistent with previous studies that revealed no evidence of LepRb-specific mRNA in these regions (Elmquist et al., 1998; Scott et al., 2009) and consistent with our finding that these regions are devoid of PSTAT3 immunoreactivity after treatment with leptin (data not shown). Thus, the midbrain contains all of the LepRb-expressing soma within the mesolimbic DA system itself. Other leptin-mediated inputs to this system must stem from projections into the mesolimbic DA system from LepRb neural soma that lie elsewhere, or less directly, via projections from second-order neurons.

To determine the regions of the mesolimbic DA system that receive direct projections from LepRb neurons, including those neurons residing elsewhere in the brain, we examined EGFP immunoreactivity in the midbrain, amygdala, and striatum of LepRb ${ }^{\text {EGFPf }}$ mice (Fig. 2). Within the midbrain, we observed EGFP immunoreactivity within the VTA, SNc, and midline nuclei (EW, RLi) that contain EGFP-IR/LepRb soma in the LepRb ${ }^{\text {EGFP }}$ animals. Since the EGFP immunoreactivity in these midbrain regions of LepRb ${ }^{\text {EGFPf }}$ animals could derive from local LepRb neurons and/or projections from LepRb neurons located elsewhere in the brain, we examined potential LepRb projections into the VTA by examining colocalization of EGFP and FG after intra-VTA FG injection in LepRb ${ }^{\text {EGFP }}$ animals (supplemental Fig. 1, available at www.jneurosci.org as supplemental material). This analysis revealed that, along with LepRb neurons in the LHA that project to the VTA (Leinninger et al., 2009), a few LepRb neurons in the periaqueductal gray (PAG) and hypothalamic preoptic area (POA), but not elsewhere in the brain, project to the VTA.

The limbic target regions of the mesolimbic DA system in LepRb ${ }^{\text {EGFPf }}$ animals contained substantial EGFP-IR projections from LepRb neurons in the extended CeA (extCeA; specifically, the $\mathrm{CeA}$ and its rostral extension, the IPAC. In contrast, other important rostral regions such as the NAc contained little EGFP immunoreactivity, although substantial EGFP-IR projections (and a few soma) were apparent in the adjacent bed nucleus of the stria terminalis (BNST) (Fig. 2). Thus, among the amygdala and striatum, the extCeA represents the major projection field of
LepRb neurons, whereas other areas receive relatively few LepRb projections. Since the amygdala (including the CeA and IPAC) contains no LepRb neurons, the EGFP immunoreactivity in these regions of LepRb ${ }^{\text {EGFPf }}$ animals must represent projections from distant LepRb neurons.

To examine the potential regulation of the midbrain and striatum/amygdala by leptin, we administered leptin $(5 \mathrm{mg} / \mathrm{kg}$, i.p., $2 \mathrm{~h}$ ) to $L e p^{o b / o b}$ animals (which are leptin deficient and highly leptin sensitive) and examined the phosphorylation of CREB by IHC (pCREB immunoreactivity) (Fig. 3). This analysis revealed that leptin promoted the severalfold induction of pCREB immunoreactivity in the VTA, CeA, and IPAC, but neither in the adjacent basolateral amygdala (BLA) nor the NAc, consistent with the leptin-mediated regulation of the extCeA projection field identified in this analysis. Thus, LepRb neurons densely innervate and modulate the activity of the extCeA.

\section{VTA LepRb neurons primarily innervate the CeA and IPAC} To determine the extent to which LepRb projections into the CeA and IPAC might derive from the well known AgRP- or POMCexpressing LepRb neurons of the ARC, we examined AgRP and POMC immunoreactivity and their potential colocalization with EGFP immunoreactivity in the extended amygdala and paraventricular hypothalamic nucleus $(\mathrm{PVH})$ of LepRb ${ }^{\text {EGFPf }}$ mice (supplemental Fig. 2, available at www.jneurosci.org as supplemental material). Although this analysis revealed the expected copious 

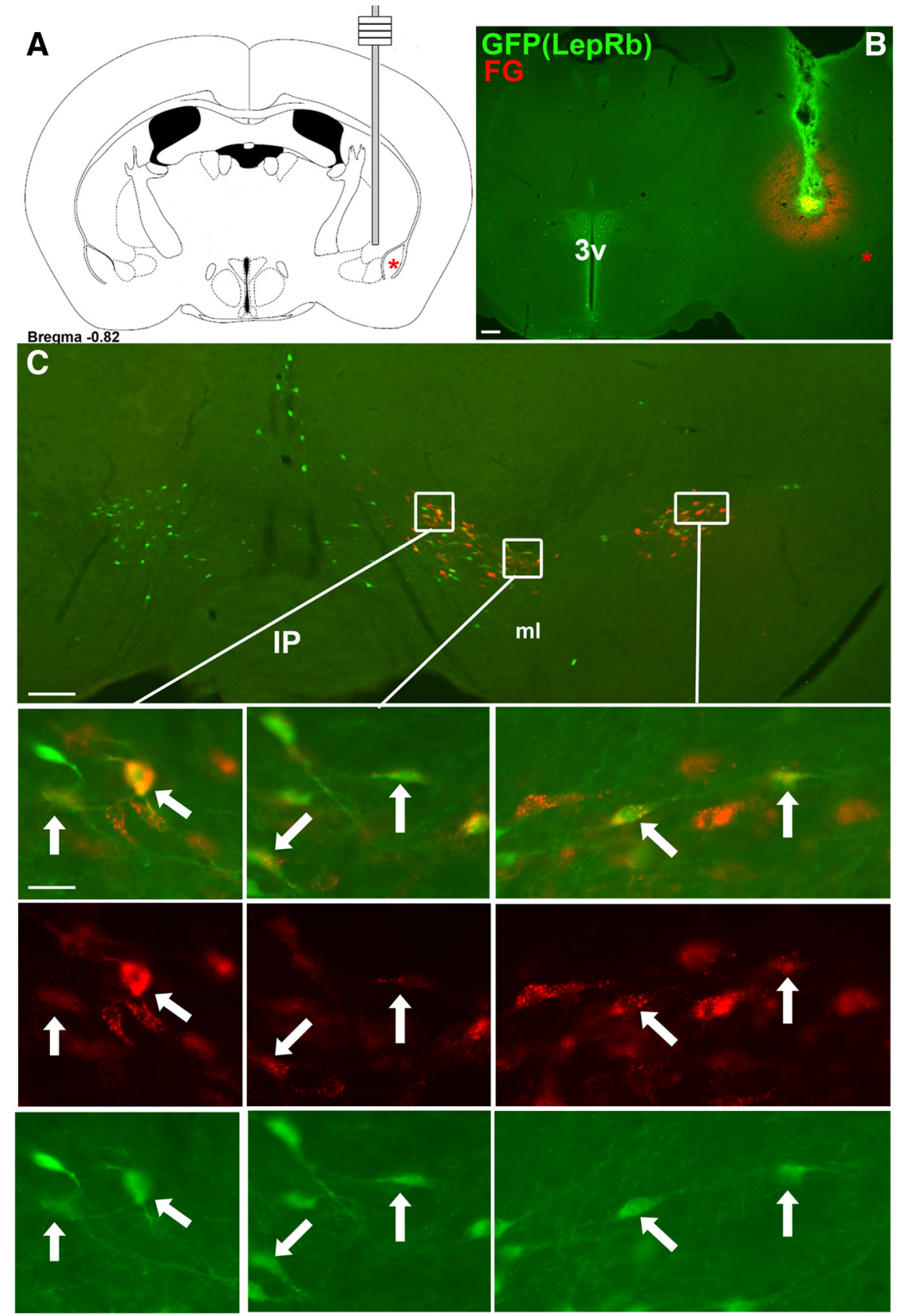

Figure 7. Retrograde tracing from IPAC labels VTA LepRb neurons. The retrograde tracer FG was stereotaxically injected into the IPAC of LepRb ${ }^{\mathrm{EGFP}}$ animals to determine the potential projection of VTA LeRb neurons to the IPAC by colocalization of FG and EGFP immunoreactivity. $\boldsymbol{A}, \boldsymbol{B}$, Schematic diagram $(\boldsymbol{A})$ and fluorescent image ( $\boldsymbol{B}$; red, FG; green, EGFP) of the IPAC injection site in a representative animal. $C$, Distribution of FG- and EGFP-IR neurons in the VTA. Images below are digital zooms of the boxed areas showing (top to bottom) merged images, FG immunoreactivity, and EGFP immunoreactivity. Arrows indicate colocalized neurons. Red asterisks indicate the BLA. Scale bars: B, C, $200 \mu \mathrm{m}$; insets, $20 \mu \mathrm{m}$. IP, Interpeduncular nucleus; ml, medial lemniscus; $3 \mathrm{v}$, third ventricle.

colocalization of EGFPf with AgRP and POMC in the PVH (a major projection target of ARC neurons), the few AgRP- and POMC-IR axons in the amygdala mostly lay outside the CeA and IPAC regions that are densely innervated by LepRb/EGFPf projections, suggesting that the LepRb projections to the extCeA derive from LepRb neurons other than those in the ARC.

Conventional anterograde tracing studies have demonstrated the projection of VTA neurons into multiple limbic brain regions, including the NAc, extended amygdala, and other areas. Such studies do not differentiate the projections of LepRb- expressing cells from those of other VTA neurons, however. To define projections specifically from LepRb-expressing soma in the VTA, we thus used Ad-iZ-EGFPf, which merges the use of EGFPf-mediated tracing with the cre-inducible system (for LepRb specificity) and adenoviral stereotaxic injection (for anatomic specificity) (Fig. 1A) (Leinninger et al., 2009; Leshan et al., 2009). We administered Ad-iZ/ EGFPf into the VTA of LepRb ${ }^{\text {cre }}$ mice and perfused them $5 \mathrm{~d}$ later for immunofluorescent analysis. Whereas administration of Ad-iZ/EGFPf produced copious EGFPf expression in LepRb ${ }^{\text {cre }}$ mice (Figs. 4, 5), no EGFPf expression was detected in wild-type animals (data not shown), confirming the specificity of EGFPf expression for the presence of cre recombinase.

Some Ad-iZ/EGFPf injections labeled LepRb neurons that were mostly confined to the VTA (Fig. 4), whereas others tended to target LepRb neurons in midline structures, such as the RLi (Fig. 5), or included lateral areas, such as the SNc (supplemental Fig. 3, available at www.jneurosci.org as supplemental material). Injections confined within the VTA revealed the dense innervation of the CeA and IPAC by VTA LepRb neurons, along with the paucity of projections from LepRb VTA neurons to the NAc. Close examination of the EGFP-IR projections from VTA LepRb neurons into the CeA and IPAC revealed a "beads-on-a-string" appearance consistent with synaptic terminals in these projection fields. Thus, these data reveal that LepRb-expressing VTA neurons primarily innervate the CeA and IPAC, not the NAc.

Whereas the distribution of axonal labeling from midline-centered injections overlapped substantially with that of VTA labeling, tracing from these midline midbrain LepRb neurons produced more widespread EGFP-IR projections (Fig. 5). In addition to demonstrating projections to extCeA nuclei (CeA and IPAC), these midline injections demonstrated some modest innervation of the NAc relative to that observed in VTA-focused injections. These data suggest that the LepRb projections into the CeA and IPAC that are visualized in LepRb ${ }^{\text {EGFPf }}$ mice arise from LepRb neurons throughout the midbrain, whereas the relatively small number of LepRb neurons that innervate the NAc may derive from midline midbrain structures, such as the RLi. Examination of projections from mice in which the viral injection included SNc (as well as VTA) labeling revealed substantial additional projections to the dorsal striatum (supplemental Fig. 3, available at www.jneurosci.org as supplemental material), suggesting that many $\mathrm{SNc}$ LepRb neurons project to the dorsal striatum, as for the majority of SNc neurons. 
Retrograde tracing experiments confirm the distribution of amygdala- and striatal-projecting LepRb neurons

To examine these circuits more closely and to verify the projection patterns of VTA and midline midbrain neurons, we used retrograde tracing with FG from the CeA, IPAC, and NAc in LepRb ${ }^{\text {EGFP }}$ mice to determine the location of LepRb neurons that project to each of these regions (Figs. 6-8). After the injection of FG into the $\mathrm{CeA}$, the midbrain demonstrated accumulation of FG predominantly in the VTA, with few FG-IR neurons seen in the RLi and substantia nigra (Fig. 6). Many VTA LepRb neurons, primarily those clustered in the dorsal portions of the VTA, accumulated FG from the CeA. CeA FG failed to accumulate in EGFP-containing LepRb neurons outside of the VTA (data not shown), suggesting that essentially all LepRb projections to the CeA arise from VTA LepRb neurons. Triple-labeled immunofluorescence for EGFP, FG, and TH in these sections confirmed the expression of $\mathrm{TH}$ in some CeA-projecting VTA LepRb neurons, consistent with the DAergic nature of some of these neurons (supplemental Fig. 4, available at www.jneurosci.org as supplemental material).

After injection of FG into the IPAC, concentrated FG immunoreactivity was seen in lateral midbrain nuclei of these animals, especially the SNc and lateral portions of the VTA (Fig. 7). No FG tracing extended to LepRb-containing midline nuclei. Substantial colocalization of EGFP and FG was seen in both the VTA and the SNc (Fig. 7). As for CeA-labeled LepRb VTA neurons, triple-labeled immunofluorescence for EGFP, FG, and $\mathrm{TH}$ in these sections confirmed the expression of $\mathrm{TH}$ in some IPAC-projecting VTA LepRb neurons, consistent with their DAergic nature (supplemental Fig. 4, available at www. jneurosci.org as supplemental material).

After FG injection in to the NAc, strong and extensive FG immunoreactivity was observed in the midbrain, including in the VTA, SN, and some midline nuclei (Fig. 8). Interestingly, although EGFP-expressing LepRb VTA neurons were surrounded by VTA neurons that accumulated FG from the NAc, LepRb neurons were not among these NAc-projecting VTA neurons. In contrast, a few RLi LepRb neurons accumulated FG from the NAc. Triplelabeled immunofluorescence for EGFP, FG, and TH in these sections failed to detect $\mathrm{TH}$ in NAc-projecting midbrain LepRb neurons (supplemental Fig. 4, available at www.jneurosci.org as supplemental material). Thus, DAergic VTA LepRb neurons project to the CeA and IPAC, but not to the NAc, whereas midline midbrain LepRb neurons, such as those in the RLi, send a small number of projections to the NAc in addition to heavily innervating the extCeA.
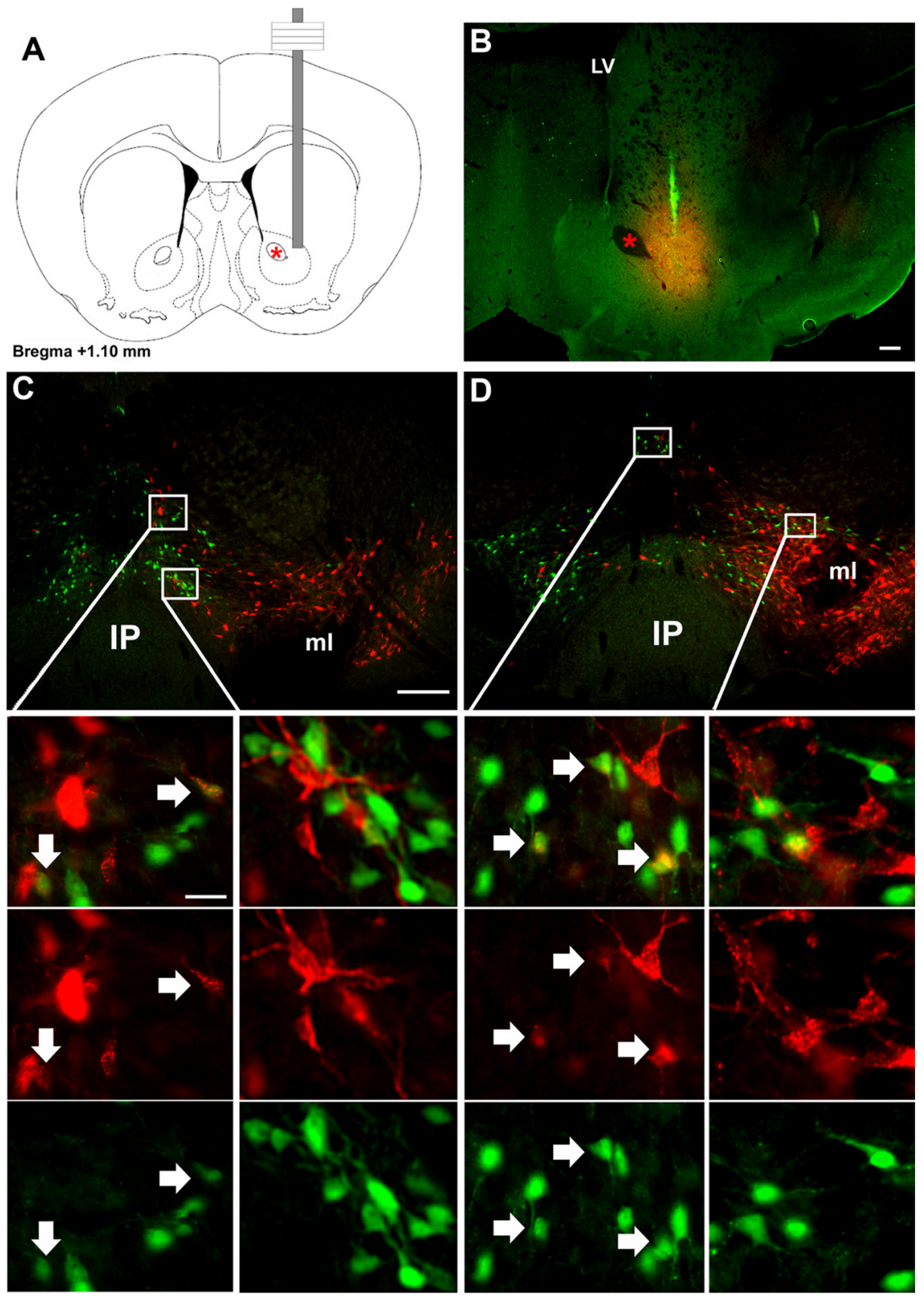

Figure 8. Retrograde tracing from NAc labels midline midbrain but not VTA LepRb neurons. The retrograde tracer FG was stereotaxically injected into the NAc of LepRb ${ }^{\mathrm{EGFP}}$ animals to determine the potential projection of VTA LeRb neurons to the NAc by colocalization of FG and EGFP immunoreactivity. $\boldsymbol{A}, \boldsymbol{B}$, Schematic diagram $(\boldsymbol{A})$ and fluorescent image ( $\boldsymbol{B}$; red, FG; green, EGFP) of the NAc injection site in a representative animal. $C, D$, Distribution of FG- and EGFP-IR neurons in the VTA. Images below are digital zooms of the boxed areas showing (top to bottom) merged images, FG immunoreactivity, and EGFP immunoreactivity. Arrows indicate colocalized neurons. Red asterisks indicate the anterior commissure. Scale bars: B, C, $200 \mu \mathrm{m}$; insets, $25 \mu \mathrm{m}$. IP, Interpeduncular nucleus; $\mathrm{ml}$, medial lemniscus; $\mathrm{LV}$, lateral ventricle.

LepRb neurons synapse with and regulate CeA CART neurons To gain insight into the CeA neural targets of VTA LepRb neurons, we developed and used the $I Z / W A P$ transgenic mouse strain, which mediates cre-inducible expression of the transsynaptic tracer WGA under control of the CMV promoter (Fig. $9 A)$. Although this strain is similar in principle to a previously described cre-inducible WGA line (Braz et al., 2002), the previous strain demonstrated little transgene expression in LepRbexpressing brain regions, presumably as a consequence of the transgene insertion site. We crossed these new $i Z / W A P$ mice to the LepRb ${ }^{\text {cre }}$ background to produce LepRb ${ }^{\text {WGA }}$ mice with WGA expression in LepRb neurons throughout the brain, thereby pro- 

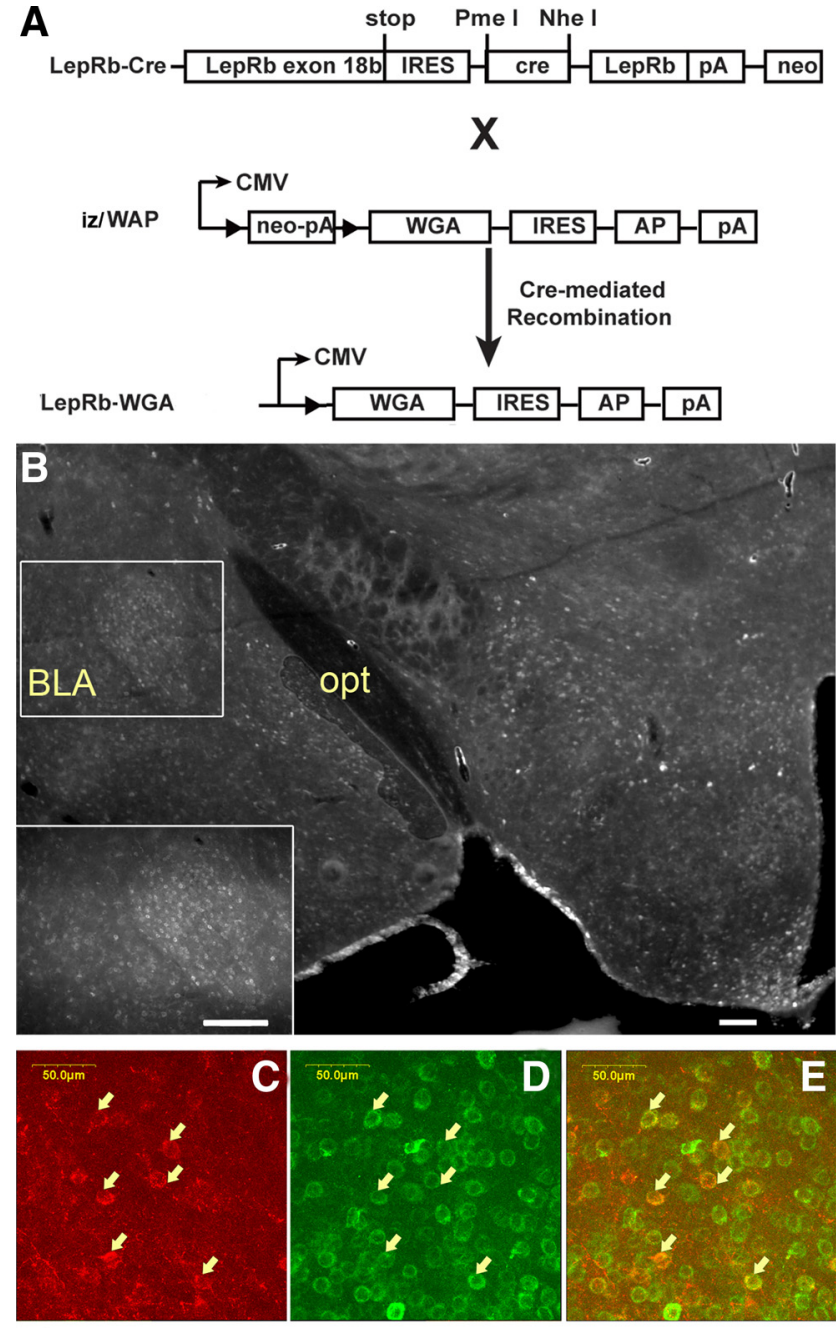

$\mathbf{F}$

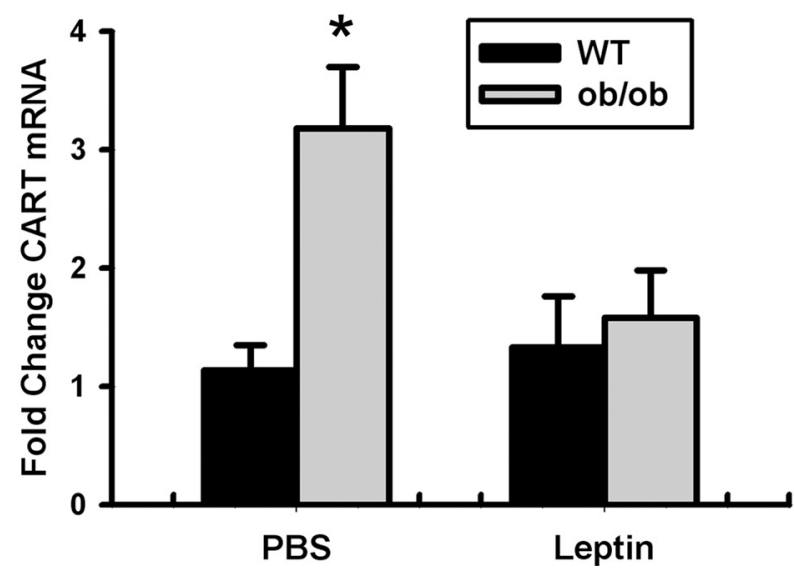

Figure 9. Identification of CART-expressing CeA neurons as targets of leptin action. A, Schematic diagram showing the generation of LepRb-WGA mice. Lepr ${ }^{\text {cre }}$ mice were crossed with iZ/WAP transgenic mice to mediate the expression of the trans-synaptic tracer WGA in LepRb neurons. IRES, Internal ribosome entry site; AP, alkaline phosphatase; $\mathrm{pA}$, polyadenylation site. $B$, WGA immunoreactivity in the hypothalamus and amygdala of a LepRb-WGA mouse. opt, optic tract. Inset, Higher-magnification image showing WGA immunoreactivity in the CeA. Scale bars, $200 \mu \mathrm{m}$. $\boldsymbol{C}-\boldsymbol{E}$, WGA-IR ( $\boldsymbol{C}$, green), CART-IR ( $\boldsymbol{D}$, red), and merged $(\boldsymbol{E})$ confocal images from the CeA of a LepRb-WGA mouse. Arrows indicate colocalized neurons. Scale bars are as indicated. $\boldsymbol{F}$, Wild-type (WT) and leptin-deficient $L e p^{o b / o b}(o b / o b)$ mice were treated with leptin $(5 \mathrm{mg} / \mathrm{kg}$, i.p.) or vehicle $12 \mathrm{~h}$ for $24 \mathrm{~h}$ before dissection and mRNA extraction from the CeA. Expression of Cart mRNA was quantified by quantitative PCR and is plotted as mean \pm SEM. $n=9-10$ per group; ${ }^{*} p<0.05$, compared with WT by ANOVA.

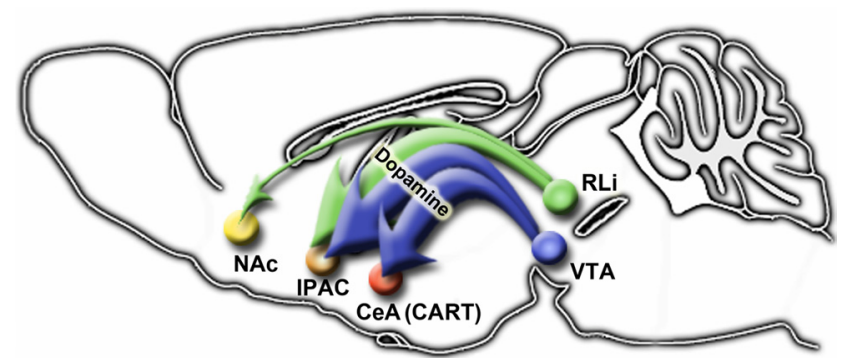

Figure 10. LepRb neurons originating in the midbrain have specific and circumscribed targets in striatal projection regions. Model describing projection patterns of LepRb neurons that originate in the VTA, which are primarily DAergic and project extensively to the CeA and IPAC; within the CeA, these projections innervate and regulate CART neurons. LepRb neurons that originate in the midline RLi project primarily to the IPAC but also send some projections to the NAC

moting WGA accumulation in the synaptic targets of LepRb neurons (Fig. 9A). Examination of WGA immunoreactivity in these LepRb ${ }^{\text {WGA }}$ animals revealed the presence of WGA in regions receiving projections from $L e p R b$ neurons, including a dense cluster of WGA-IR neurons in the CeA (Fig. 9B). In contrast, areas receiving few LepRb projections (including the BLA and NAc) revealed little WGA immunoreactivity, and mice lacking either the iZ/WAP or Lepr ${ }^{\text {cre }}$ allele displayed no WGA immunoreactivity (data not shown). Standard immunofluorescence for the neuropeptide CART revealed the presence of WGA immunoreactivity in most CeA CART-IR neurons, suggesting that LepRb neurons form synapses with CART-expressing neurons in the CeA (Fig. $9 C-E$ ). To examine the potential functional relevance of this circuit, we compared the expression of Cart mRNA in the CeA of wild-type or leptin-deficient $L e p^{o b / o b}$ animals after treatment with leptin $(5 \mathrm{mg} / \mathrm{kg}$, i.p.) or vehicle for $24 \mathrm{~h}$ (Fig. $9 F)$. This analysis revealed the more than threefold induction of Cart mRNA in Lep ${ }^{o b / o b}$ relative to wild-type animals and the normalization of CeA Cart mRNA by leptin treatment in Lep ${ }^{o b / o b}$ mice. Together with the finding that VTA (but not other) LepRb neurons project to the CeA, these data suggest that VTA LepRb neurons form active synapses with CART-expressing CeA neurons and regulate Cart expression in these neurons.

\section{Discussion}

Our use of LepRb-specific genetic and adenoviral systems reveals a limited set of direct interactions between LepRb neurons and brain regions of the mesolimbic DA system: the midbrain contains LepRb neurons and receives projections from LepRb neurons of the LHA (Leinninger et al., 2009) and, to a lesser extent, the PAG and POA. Most LepRb projections into the amygdala and striatum target the CeA and IPAC components of the ext$\mathrm{CeA}$, where leptin regulates neuronal activity, as assessed by pCREB immunoreactivity. These LepRb projections to the extCeA derive from the midbrain, including the VTA (Fig. 10), and VTA LepRb neurons project solely to the extCeA. Within the $\mathrm{CeA}$, LepRb projections synapse with CART neurons and regulate their gene expression. The LepRb neurons that originate in the midline nuclei of the midbrain (e.g., RLi) send a few projections to the NAc in addition to densely innervating the extCeA. The CeA and IPAC receive the vast majority of projections from both VTA and midline midbrain LepRb neurons, however. This specificity of projections from LepRb VTA neurons fits well with other recent findings that describe discrete patterns of projection, gene expression, and functional properties for subsets of VTA DA 
neurons (Ikemoto, 2007; Lammel et al., 2008; Margolis et al., 2008).

As for all experimental tools, the Ad-iZ/EGFPf and LepRb ${ }^{\text {EGFPf }}$ systems possess inherent limitations. The expression of EGFPf in the brains of transgenic LepRb ${ }^{\text {EGFPf }}$ mice is modest compared with that mediated by the higher copy number and stronger promoter system of the Ad-iZ/EGFPf, rendering it difficult to detect the relatively weak innervation of the NAc by LepRb neurons that could be observed with midline midbrain injection of Ad-iZ/ EGFPf. Overall, the LepRb ${ }^{\text {EGFPf }}$ mice clearly reveal the much greater density of LepRb projections into the extended amygdala than the NAc, however.

For Ad-iZ/EGFPf studies, the necessity of using mice (specifically, transgenic animals with cre recombinase expression in LepRb neurons) with their small brains and resultant close spacing among midbrain nuclei limits the extent to which it is possible to isolate VTA relative to RLi LepRb labeling. The advantages of these systems, however, include the strict specificity for LepRb neurons and the prospective interrogation of projections from LepRb neurons or anatomically defined subpopulations of LepRb neurons. In this case, the use of the Ad-iZ/EGFPf system revealed the previously unsuspected dominant innervation of the CeA and IPAC by midbrain LepRb neurons, which we then confirmed by standard tracing methods.

Although others have previously demonstrated the existence of LepRb-expressing VTA neurons (Figlewicz et al., 2006; Fulton et al., 2006; Hommel et al., 2006), the potential manner(s) in which LepRb VTA neurons might differ from other VTA neurons was not clear. Here, we demonstrate the virtually exclusive innervation of the CeA and IPAC by LepRb VTA neurons, which contrasts with the predominant innervation of the NAc by the larger general population of VTA neurons. Although Fulton et al. (2006) previously suggested that midbrain LepRb neurons innervate the NAc, the location of the LepRb neurons in question was not clear from the data shown (Fulton et al., 2006). Based on our present results, we surmise that the NAc-projecting LepRb midbrain neurons identified lie within the RLi or other midline areas of the midbrain, rather than the VTA DA LepRb neurons.

The laboratory of R. J. DiLeone has directly examined the role for midbrain LepRb action in long-term energy balance: direct bilateral application of leptin to the midbrain of normal rats decreased food intake over $24 \mathrm{~h}$, and AAV-RNAi-mediated knockdown of midbrain LepRb in rats increased food intake, activity, and sucrose preference without altering body weight (Hommel et al., 2006). These data suggest a role for midbrain LepRb neurons in the modulation of feeding and activity. Our present findings regarding the projection patterns of VTA and midbrain LepRb neurons suggest the possibility that these LepRb neurons may also control behaviors not previously examined, however, and that previous data regarding the function of these neurons should be considered in this light.

That leptin promotes extCeA CREB phosphorylation and modulates CeA Cart expression suggests the functional relevance of the LepRb VTA $\rightarrow$ extCeA projections for CeA physiology. In addition to promoting incentive salience, midbrain neurons in general (and VTA DA neurons specifically) also function in the modulation of anxiety behaviors and in learning related to aversive stimuli, and aversive signals from the VTA may be conveyed by specific subsets of midbrain neurons (Matsumoto and Hikosaka, 2009). The well known role of the CeA in anxiety and the behavioral response to aversive stimuli suggests a potential role for amygdala-projecting VTA neurons in such reactions. Indeed, leptin decreases anxiety-like behaviors in leptin-deficient and normal animals (Liu et al., 2009). Additionally, evidence that CeA-projecting LepRb neurons (i.e., VTA LepRb neurons) synapse with CeA CART neurons and regulate their Cart expression suggests that leptin may modulate CART-associated behaviors in the amygdala. Increased CeA Cart expression correlates with anxiety, depression, and stress responses under a variety of conditions (Hunter et al., 2007; Dandekar et al., 2008a,b, 2009). The majority (95 $\pm 1 \%$ ) of CeA CART neurons express Gad1, which produces GABA (supplemental Fig. 5, available at www.jneurosci.org as supplemental material); hence, GABA signaling by CeA CART neurons also likely participates in the action of VTA LepRb neurons.

Whereas the effect of leptin on the firing and gene expression in LepRb VTA neurons specifically remains unclear, because of the inability to record specifically from LepRb neurons, Hommel et al. suggested that leptin hyperpolarizes VTA DA neurons (Hommel et al., 2006; Roseberry et al., 2007). Indeed, our finding that leptin decreases Cart expression in the CeA not only suggests the functional relevance of this circuit but is consistent with the notion that leptin decreases DA efflux into the CeA, since DA promotes Cart expression in the CeA and elsewhere (Fagergren and Hurd, 1999). One reasonable hypothesis thus suggests that leptin action via VTA LepRb neurons regulates the extCeA and CeA-directed behaviors. A great deal more work will be required to fully examine this issue, however.

Previous data also demonstrate that leptin promotes the expression of TH and increases vesicular DA stores in the VTA and NAc (Fulton et al., 2006; Roseberry et al., 2007); recent data suggest that leptin action via LHA LepRb neurons plays a major role in these effects, however (Leinninger et al., 2009), consistent with our present finding that the LHA contributes substantial LepRb projections into the VTA. The modulation of DA production and content in the VTA by this leptin-controlled pathway may contribute to the modulation of incentive value, the response to drugs of abuse, and other DA-dependent behaviors.

Clearly, leptin also controls the mesolimbic DA system by less direct means, involving additional synapses. Indeed, lateral hypothalamic melanin concentrating hormone $(\mathrm{MCH})$ and orexin (OX) neurons project to the NAc and VTA, respectively, and modulate the mesolimbic DA system and feeding (Bartke et al., 2001). Neither of these leptin-inhibited populations of LHA neurons express LepRb (Leinninger et al., 2009), however, and leptin must act trans-synaptically to regulate $\mathrm{MCH}$ and $\mathrm{OX}$ neurons.

Overall, our data reveal a specific and circumscribed set of projections from LepRb neurons into the extCeA and indicate that these projections stem primarily from midbrain (especially VTA) LepRb neurons. Based on these data and our finding that leptin controls the activity and Cart gene expression in CeA neurons, midbrain leptin action likely controls an amygdala-specific subset of the functions ascribed to the larger mesolimbic DA system.

\section{References}

Abe H, Yanagawa Y, Kanbara K, Maemura K, Hayasaki H, Azuma H, Obata K, Katsuoka Y, Yabumoto M, Watanabe M (2005) Epithelial localization of green fluorescent protein-positive cells in epididymis of the GAD67-GFP knock-in mouse. J Androl 26:568-577.

Allen T, van Tuyl M, Iyengar P, Jothy S, Post M, Tsao MS, Lobe CG (2006) Grg1 acts as a lung-specific oncogene in a transgenic mouse model. Cancer Res 66:1294-1301.

Balthasar N, Coppari R, McMinn J, Liu SM, Lee CE, Tang V, Kenny CD, McGovern RA, Chua SC Jr, Elmquist JK, Lowell BB (2004) Leptin receptor signaling in POMC neurons is required for normal body weight homeostasis. Neuron 42:983-991. 
Bartke A, Coschigano K, Kopchick J, Chandrashekar V, Mattison J, Kinney B, Hauck S (2001) Genes that prolong life: relationships of growth hormone and growth to aging and life span. J Gerontol A Biol Sci Med Sci 56:B340-B349.

Berthoud HR (2007) Interactions between the "cognitive" and "metabolic" brain in the control of food intake. Physiol Behav 91:486-498.

Braz JM, Rico B, Basbaum AI (2002) Transneuronal tracing of diverse CNS circuits by Cre-mediated induction of wheat germ agglutinin in transgenic mice. Proc Natl Acad Sci U S A 99:15148-15153.

Cohen P, Zhao C, Cai X, Montez JM, Rohani SC, Feinstein P, Mombaerts P, Friedman JM (2001) Selective deletion of leptin receptor in neurons leads to obesity. J Clin Invest 108:1113-1121.

Dandekar MP, Singru PS, Kokare DM, Lechan RM, Thim L, Clausen JT, Subhedar NK (2008a) Importance of cocaine- and amphetamine-regulated transcript peptide in the central nucleus of amygdala in anxiogenic responses induced by ethanol withdrawal. Neuropsychopharmacology 33:1127-1136.

Dandekar MP, Singru PS, Kokare DM, Subhedar NK (2008b) Transient upregulation of cocaine- and amphetamine-regulated transcript peptide (CART) immunoreactivity following ethanol withdrawal in rat hypothalamus. Brain Res 1240:119-131.

Dandekar MP, Singru PS, Kokare DM, Subhedar NK (2009) Cocaine- and amphetamine-regulated transcript peptide plays a role in the manifestation of depression: social isolation and olfactory bulbectomy models reveal unifying principles. Neuropsychopharmacology 34:1288-1300.

de Luca C, Kowalski TJ, Zhang Y, Elmquist JK, Lee C, Kilimann MW, Ludwig T, Liu SM, Chua SC Jr (2005) Complete rescue of obesity, diabetes, and infertility in $\mathrm{db} / \mathrm{db}$ mice by neuron-specific LEPR-B transgenes. J Clin Invest 115:3484-3493.

Dhillon H, Zigman JM, Ye C, Lee CE, McGovern RA, Tang V, Kenny CD, Christiansen LM, White RD, Edelstein EA, Coppari R, Balthasar N, Cowley MA, Chua S Jr, Elmquist JK, Lowell BB (2006) Leptin directly activates SF1 neurons in the VMH, and this action by leptin is required for normal body-weight homeostasis. Neuron 49:191-203.

DiLeone RJ, Georgescu D, Nestler EJ (2003) Lateral hypothalamic neuropeptides in reward and drug addiction. Life Sci 73:759-768.

DiMicco JA, Zaretsky DV (2007) The dorsomedial hypothalamus: a new player in thermoregulation. Am J Physiol Regul Integr Comp Physiol 292:R47-R63.

Elmquist JK, Bjorbaek C, Ahima RS, Flier JS, Saper CB (1998) Distributions of leptin receptor mRNA isoforms in the rat brain. J Comp Neurol 395:535-547.

Elmquist JK, Coppari R, Balthasar N, Ichinose M, Lowell BB (2005) Identifying hypothalamic pathways controlling food intake, body weight, and glucose homeostasis. J Comp Neurol 493:63-71.

Fagergren P, Hurd YL (1999) Mesolimbic gender differences in peptide CART mRNA expression: effects of cocaine. Neuroreport 10:3449-3452.

Figlewicz DP, MacDonald Naleid A, Sipols AJ (2006) Modulation of food reward by adiposity signals. Physiol Behav 91:473-478.

Friedman JM (2002) The function of leptin in nutrition, weight, and physiology. Nutr Rev 60:S1-S14.

Fulton S, Woodside B, Shizgal P (2000) Modulation of brain reward circuitry by leptin. Science 287:125-128.

Fulton S, Pissios P, Manchon RP, Stiles L, Frank L, Pothos EN, Maratos-Flier E, Flier JS (2006) Leptin regulation of the mesoaccumbens dopamine pathway. Neuron 51:811-822.

Gao Q, Horvath TL (2007) Neurobiology of feeding and energy expenditure. Annu Rev Neurosci 30:367-398.

Grill HJ (2006) Distributed neural control of energy balance: contributions from hindbrain and hypothalamus. Obesity (Silver Spring) 14 [Suppl 5]:216S-221S.

Hayes MR, Skibicka KP, Leichner TM, Guarnieri DJ, DiLeone RJ, Bence KK, Grill HJ (2010) Endogenous leptin signaling in the caudal nucleus tractus solitarius and area postrema is required for energy balance regulation. Cell Metab 11:77-83.

Hommel JD, Trinko R, Sears RM, Georgescu D, Liu ZW, Gao XB, Thurmon JJ, Marinelli M, DiLeone RJ (2006) Leptin receptor signaling in midbrain dopamine neurons regulates feeding. Neuron 51:801-810.

Hunter RG, Bellani R, Bloss E, Costa A, Romeo RD, McEwen BS (2007)
Regulation of CART mRNA by stress and corticosteroids in the hippocampus and amygdala. Brain Res 1152:234-240.

Huo L, Gamber K, Greeley S, Silva J, Huntoon N, Leng XH, Bjorbaek C (2009) Leptin-dependent control of glucose balance and locomotor activity by POMC neurons. Cell Metab 9:537-547.

Ikemoto S (2007) Dopamine reward circuitry: two projection systems from the ventral midbrain to the nucleus accumbens-olfactory tubercle complex. Brain Res Rev 56:27-78.

Kelley AE, Baldo BA, Pratt WE (2005) A proposed hypothalamic-thalamicstriatal axis for the integration of energy balance, arousal, and food reward. J Comp Neurol 493:72-85.

Lammel S, Hetzel A, Hackel O, Jones I, Liss B, Roeper J (2008) Unique properties of mesoprefrontal neurons within a dual mesocorticolimbic dopamine system. Neuron 57:760-773.

Leinninger GM, Jo YH, Leshan RL, Louis GW, Yang H, Barrera JG, Wilson H, Jones JC, Rhodes CJ, Chua SC Jr, Diano S, Horvath TL, Seeley RJ, Becker JB, Münzberg H, Myers MG Jr (2009) Leptin acts via leptin receptorexpressing lateral hypothalamic neurons to modulate the mesolimbic dopamine system and suppress feeding. Cell Metab 10:89-98.

Leshan RL, Bjornholm M, Münzberg H, Myers MG Jr (2006) Leptin receptor signaling and action in the central nervous system. Obesity (Silver Spring) 14 [Suppl 5]:208S-212S.

Leshan RL, Louis GW, Jo YH, Rhodes CJ, Münzberg H, Myers MG Jr (2009) Direct innervation of GnRH neurons by metabolic- and sexual odorantsensing leptin receptor neurons in the hypothalamic ventral premammillary nucleus. J Neurosci 29:3138-3147.

Liu J, Garza JC, Bronner J, Kim CS, Zhang W, Lu XY (2009) Acute administration of leptin produces anxiolytic-like effects: a comparison with fluoxetine. Psychopharmacology (Berl) 207:535-545.

Lu XY, Kim CS, Frazer A, Zhang W (2006) Leptin: a potential novel antidepressant. Proc Natl Acad Sci U S A 103:1593-1598.

Margolis EB, Mitchell JM, Ishikawa J, Hjelmstad GO, Fields HL (2008) Midbrain dopamine neurons: projection target determines action potential duration and dopamine $\mathrm{D}_{2}$ receptor inhibition. J Neurosci 28:89088913.

Matsumoto M, Hikosaka O (2009) Two types of dopamine neuron distinctly convey positive and negative motivational signals. Nature 459:837-841.

Morton GJ, Niswender KD, Rhodes CJ, Myers MG Jr, Blevins JT, Baskin DG, Schwartz MW (2003) Arcuate nucleus-specific leptin receptor gene therapy attenuates the obesity phenotype of Koletsky (fak/fak) rats. Endocrinology 144:2016-2024.

Morton GJ, Cummings DE, Baskin DG, Barsh GS, Schwartz MW (2006) Central nervous system control of food intake and body weight. Nature 443:289-295.

Münzberg H, Jobst EE, Bates SH, Jones J, Villanueva E, Leshan R, Bjornholm M, Elmquist J, Sleeman M, Cowley MA, Myers MG Jr (2007) Appropriate inhibition of orexigenic hypothalamic arcuate nucleus neurons independently of leptin receptor/STAT3 signaling. J Neurosci 27:69-74.

Myers MG Jr, Münzberg H, Leinninger GM, Leshan RL (2009) The geometry of leptin action in the brain: more complicated than a simple ARC. Cell Metab 9:117-123.

Nestler EJ (2005) Is there a common molecular pathway for addiction? Nat Neurosci 8:1445-1449.

Paxinos G, Franklin KBJ (2001) The mouse brain in stereotaxic coordinates. San Diego: Academic.

Roseberry AG, Painter T, Mark GP, Williams JT (2007) Decreased vesicular somatodendritic dopamine stores in leptin-deficient mice. J Neurosci 27:7021-7027.

Scott MM, Lachey JL, Sternson SM, Lee CE, Elias CF, Friedman JM, Elmquist JK (2009) Leptin targets in the mouse brain. J Comp Neurol 514: $518-532$.

Yadav VK, Oury F, Suda N, Liu ZW, Gao XB, Confavreux C, Klemenhagen KC, Tanaka KF, Gingrich JA, Guo XE, Tecott LH, Mann JJ, Hen R, Horvath TL, Karsenty G (2009) A serotonin-dependent mechanism explains the leptin regulation of bone mass, appetite, and energy expenditure. Cell 138:976-989.

Zylka MJ, Rice FL, Anderson DJ (2005) Topographically distinct epidermal nociceptive circuits revealed by axonal tracers targeted to Mrgprd. Neuron 45:17-25. 